\title{
ACTUAL EVAPOTRANSPIRATION OF GRASSLANDS AND PLANTATIONS IN ARID ZONES
}

\author{
NiZiŃSKI, J. J. ${ }^{*}$ - ZIERNICKA-WOJTASZEK, A. - KSIĄŻEK, L. - GAWROŃSKI, K. - SKOWERA, B. - \\ ZUŚKA, Z. - WOJKOWSKI, J.
}

Faculty of Environmental Engineering and Land Surveying, University of Agriculture in Krakow, Al. Mickiewicza 24-28, 30-059 Krakow, Poland

\author{
*Corresponding author \\ e-mail: georges.nizinski@ird.fr \\ (Received 23 $3^{\text {rd }}$ Jan 2019; accepted $29^{\text {th }}$ Mar 2019)
}

\begin{abstract}
In models of global change, the course of the general circulation of the atmosphere is dependent on the planetary distribution of sources and sinks of energy; during periods of balance, energy is transported by atmospheric air and the water of the oceans. The atmosphere must thus transport the energy of the continents towards the oceans during the summer and that of the oceans towards the continents during the winter. The study of these phenomena on the continents uses data related to studies of actual evapotranspiration on a local level, which is the level presented here. Recent models of actual evapotranspiration dissociate evaporation of the soil from canopy transpiration and interception, and simulate the evolution of the structure of cover, stomatal resistances, and factors which govern vapour water flux resistance and the balance between evaporation and transpiration. In today's models which take a mechanistic approach, the difficulty of choosing income parameters has become significant, especially the problem of their initial state under a given set of environmental conditions. The objective of this paper is to point out the potential use of the Penman-Monteith formula, which has worked well for the actual evapotranspiration phenomenon of close covers and can be adapted to sparse vegetation (herbaceous savannah with areas of bare soil), while treating leaf transpiration and bare-soil evaporation separately. The actual evapotranspiration of the herbaceous savannah is limited by a boundary layer resistance of the same order of magnitude as surface resistance plotted to the stomata and leaf area index, whereas that of woody covers is limited only by surface resistance: the stomata of trees are more sensitive to the drying of the air and soil than those of herbaceous plants.
\end{abstract}

Keywords: drylands, Sudano-Sahel, sparse vegetation, Penman-Monteith equation, evapotranspiration, surface resistance

\section{Introduction}

In actual evapotranspiration models of plant cover with mechanistic vocation, the problems are (a) the choice of the most significant input parameters; and (b) their initial calibration in a given set of environmental conditions. The purpose of this paper is to present the advantages of using the Penman-Monteith formula (Monteith and Unsworth, 1990).

The actual evapotranspiration of herbaceous savannahs is limited by boundary layer resistance which is of the same order of magnitude as cover resistance, which in turn is related to stomata resistance and leaf area index, whereas the actual evapotranspiration of plantations is limited only by cover resistance: the stomata of trees are more sensitive to drying of air and soil than those of herbaceous plants.

In this article, for the estimation and modelling of actual evapotranspiration, the time-step resolution is one day; conditions are equivalent to so-called 'conservative flux' in which absorption is equal to transpiration, which is rarely the case in reality for a time-step resolution of less than one day, during which the plant is subject to dehydration and rehydration, but which is realistic for a $24-\mathrm{h}$ time-step resolution. 
Historically Penman (1948) and Monteith (1965) laid the physical foundations for calculating the evaporation of a wet surface and subsequently the actual evapotranspiration of closed plant cover.

The aim of the work described in this paper is to highlight the quality and relevance of the Penman-Monteith model. Nevertheless, on the one hand, even for continuous covers, it is necessary to refine the parameters of the canopy resistance. On the other hand, it was relevant to check the Penman Monteith model for sparse covers crops using the field experience (here the savannahs of the Sahel and the Atlantic coast of Congo); this model makes it possible to account for the actual evapotranspiration of closed plant cover (woody plants) and ought be adapted to sparse cover (woody herbaceous savannah with bare soil surfaces) by treating leaf transpiration and evaporation of bare soil separately.

\section{Materials and methods}

\section{Theory of evapotranspiration measurements}

For uniform and sufficiently large surfaces with very small slope values, sensible heat and latent heat fluxes are considered vertical and are subject to the principle of 'similarity' between the coefficients of sensible heat transfer $\left(\mathrm{k}_{\mathrm{H}}\right)$ and latent heat $\left(\mathrm{k}_{\mathrm{E}}\right)$; thus $\mathrm{k}_{\mathrm{H}} \approx \mathrm{k}_{\mathrm{E}}$. Empirical relationships between flows and vertical gradients of sensible and latent heat can be expressed in the form known as the Penman-Monteith equation (1965):

$$
E a=\frac{E T_{0}}{\left(1+\left(\frac{\gamma}{\Delta+\gamma}\right) \cdot\left(\frac{r_{s t}}{L A I \cdot r_{a}}\right)\right)}
$$

where: Ea is actual evapotranspiration $\left(\mathrm{mm} \mathrm{day}^{-1}\right) ; \mathrm{ET}_{0}$ is potential evapotranspiration $\left(\mathrm{mm} \mathrm{day}^{-1}\right)$ (in this paper, we applied an equation associated with the FAO formula used by Allen et al., 1998); $\gamma$ is the psychrometric constant $\left(\mathrm{mb} \mathrm{K}^{-1}\right) ; \Delta$ is the slope of the saturation vapour pressure vs temperature curve $\left(\right.$ bar K $\left.^{-1}\right) ; r_{s t}$ is stomatal resistance ( $\mathrm{s}$ $\left.\mathrm{cm}^{-1}\right) ; L A I$ is leaf area index; $\left(\mathrm{m}^{2} \mathrm{~m}^{-2}\right) ; \mathrm{r}_{\mathrm{a}}$ is aerodynamic resistance $\left(\mathrm{s} \mathrm{cm}^{-1}\right)$.

\section{Crop boundary layer diffusion resistance}

The Penman-Monteith equation involves the quantification of aerodynamic resistance of plant cover $\left(r_{a}\right)$, crop cover resistance (cover resistance) $\left(\mathrm{r}_{\mathrm{c}}\right)$, and climatic variables. Aerodynamic resistance is a physical quantity that accounts for the diffusion of heat or water vapour from leaf surfaces into the atmosphere (Fig. 1).

Cover resistance $\left(r_{c}\right)$ is chiefly a biological term that accounts for the diffusion of water vapour from leaves in terms of a leaf's stomatal resistance to such diffusion, $r_{\text {st }}$. The following simplified equations are used for closed plant cover (Saugier, 1996):

$$
r_{a}=\frac{r_{b}}{L A I}+r_{a(1)}
$$




$$
r_{c}=\frac{r_{b}+r_{s t}}{L A I}+r_{a(1)}
$$

where: $r_{b}$ is leaf boundary layer resistance $\left(\mathrm{s} \mathrm{cm}^{-1}\right) ; L A I$ is leaf area index $\left(\mathrm{m}^{2} \mathrm{~m}^{-2}\right) ; \mathrm{r}_{\mathrm{a}(1)}$ is aerodynamic resistance $\left(\mathrm{s} \mathrm{cm}^{-1}\right) ; \mathrm{r}_{\mathrm{st}}$ is stomatal resistance $\left(\mathrm{s} \mathrm{cm}^{-1}\right)$.

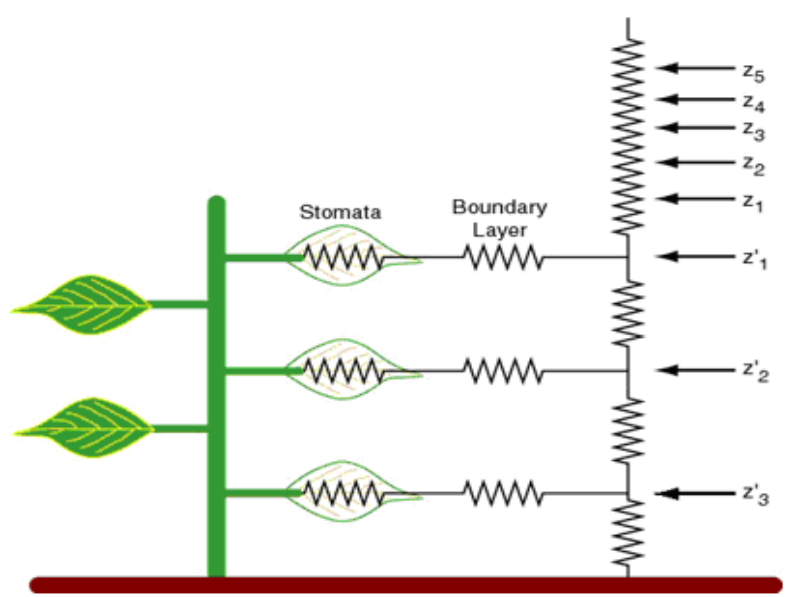

Figure 1. Model schematically showing the resistance of given vegetation cover $\left(r_{c}\right)$. Resistance levels are represented by serrated segments. In the 'big leaf' model (Monteith, 1965) the resistance of the vegetation cover $\left(r_{c}\right)$ refers to one vegetation layer

These equations assume that the leaf resistances of the entire canopy are identical at all times, but this is not actually the case: from the top to the bottom of the canopy, $r_{b}$ increases due to a decrease in wind speed, and $r_{s t}$ increases due to a decrease in global radiation $\left(\mathrm{R}_{\mathrm{g}}\right)$ (see the detailed analysis by Saugier, 1996); in addition, leaf growth conditions depend on the position of leaves in the canopy architecture; the top and bottom leaves do not share the same physiological characteristics (leaves are designated 'shadow' and 'light').

\section{Aerodynamic resistance}

Aerodynamic resistance is composed of leaf boundary layer resistance to the diffusion of heat or water vapour and resistance of the air between the middle of the canopy (average height of the canopy) and the height above the canopy where it is technically possible to measure meteorological variables. We calculate $r_{a}$ or its inverse, $1 / \mathrm{r}_{\mathrm{a}}=\mathrm{g}_{\mathrm{a}}$, and aerodynamic conductance, assuming equality between the transfer coefficients for heat $\left(\mathrm{k}_{\mathrm{H}}\right)$ and for momentum $\left(\mathrm{k}_{\mathrm{V}}\right)$ :

$$
r_{a}=\left(\frac{1}{\left(k^{2} \cdot u_{2 m}\right)}\right) \cdot\left[\ln \left(\frac{z-d}{z_{0}}\right)\right]^{2}
$$

where $r_{a}$ is aerodynamic resistance $\left(\mathrm{s} \mathrm{cm}^{-1}\right)$; $\mathrm{k}$ is the von Kármán constant $(0.39)$; $\mathrm{u}_{2 \mathrm{M}}$ is wind speed $\left(\mathrm{m} \mathrm{s}^{-1}\right) ; z$ is height above ground $(\mathrm{m}) ; \mathrm{z}_{0}$ is roughness height $(\mathrm{m}) ; d$ is zero plane displacement height $(\mathrm{m})$.

For tree-covered areas we calculated $\mathrm{g}_{\mathrm{a}}$ from stand height as well: 


$$
\begin{aligned}
& \mathrm{d}=0.75 \mathrm{~h} \\
& \mathrm{z}_{0}=0.1 \mathrm{~h}
\end{aligned}
$$

where $\mathrm{h}$ is mean tree height $(\mathrm{m})$.

\section{Cover resistance}

Canopy resistance depends on the stomatal resistance of the leaves and the leaf area index of the canopy in question. Canopy transpiration is the sum of transpirations of all leaves; each leaf is characterised by instantaneous stomatal resistance which is dependent on its own physiological characteristics and the microclimate to which it is subjected.

In terms of stomatal resistance: stomatal movements (depending on the turgor of the guard cells) are governed by global radiation, air vapour pressure, soil water content, and leaf water status.

The mechanisms through which stomata respond to the last three factors are still being discussed:

- Humidity of the atmosphere: more and more often, it is said that stomata are dependent on relative air humidity, and may also be dependent on the deficit of saturation of the air associated with the flow of water inside the leaf; however, it is unclear what kind of mechanism is involved;

- Soil water content status: the influence of soil water content on stomatal movements has long been explained by its action on leaf water status, i.e. a decrease in soil water potential leads to a decrease in leaf water potential resulting from a threshold potential stomatal closure. However, today we know that a plant that is adequately supplied with water but subject to high soil water potentials will close its stomata: roots, in contact with dry soil, synthesise abscisic acid which acts directly on the stomata, irrespective of the water status of the plant. Among the species we studied, Balanites aegyptiaca may correspond to this scenario: in the course of soil drying, when higher soil layers contain no more water available for the plant, but deeper layers still contain available water, Balanites aegyptiaca will close its stomata during the days, even from late at night until sunrise, there may be no stomatal opening);

- Plant water status: there is no simple causal relationship between stomatal movements and leaf water potential. Thus, with equal leaf water potential, the stomata are closed at night and open during the day. Depending on the species, soil drying causes stomatal closure, with or without an impact on leaf water potential. The species we worked on correspond to the first case, with the exception of Balanites aegyptiaca. During a period of soil drying, Balanites aegyptiaca employs a leaf area index modification strategy (falling leaves) associated with maintaining a high level of leaf water potential for the remaining leaves (during a period corresponding to a drought). Among the strategies of a plant subject to drought are those relating to the flow of water in the plant and those relating to the distribution of assimilated materials; however, in general, a larger share of carbon goes to the roots, and/or reduction of leaf growth and acceleration of senescence occurs.

Stomatal resistance is usually systematically measured in the field, as we have done here, but currently only empirical models are available to account for variations in this resistance along with environmental factors. The stomatal resistance of a leaf can be calculated, using 
the empirical models of Jarvis (1976), from the relationships between the minimal stomatal resistance of a leaf, leaf water potential, global radiation, air saturation deficit, and soil water content.

Stomatal resistance depends on minimal stomatal resistance, a specific point value corresponding to a situation characterised by the absence of water stress (soil and plant). Minimal stomatal resistance changes over time, from a leaf's appearance to its senescence; it decreases to a minimum value, then rises again (morphological and physiological evolution of the leaf), as we have observed in the species we studied (Fig. 6a-d). In deciduous species (oaks, Acacia, Rubber tree), where all of the leaves of the canopy evolve grosso modo synchronously, canopy resistance is a function of minimum stomatal resistance and leaf area index.

In evergreen species (Eucalyptus spp.), the degree of dependence of canopy resistance on minimum stomatal resistance depends on the renewal rate of the leaves, since leaves of varying ages coexist in the cover (sampling problem).

To estimate historical crop cover resistance, we began by assuming that all leaves were similar (i.e. shared the same physiological characteristics, even microclimate).

- Katerji and Perrier (1985) estimated the variability of stomatal resistance throughout the canopy and divided the cover into several layers to which they applied the equation given above (Eqs. 2 and 3).

- Saugier and Katerji (1991) proposed a calculation based on the exponential decay of global radiation and the cumulative leaf area index from the top of the canopy, as well as on integration of the variation of stomatal resistance with received global radiation.

- Other authors calculate cover resistance $\left(r_{c}\right)$ from latent heat flux measurements above the canopy using micrometeorologic methods, reversing the PenmanMonteith equation; closed crop cover is considered a 'big leaf' whose aerodynamic resistance must be a known value.

We started by using the Jarvis (1976) model. Then, for the savannah of the Congolese littoral, we used an inverse Penman-Monteith equation, with parallel measures of stomatal resistance and environmental factors; this latter approach enables deterministic analysis of cover resistance. Measurement of leaf area index is decisive in estimating this resistance.

\section{Climate variables}

Another variable which is difficult to estimate using the Penman-Monteith equation is the air saturation deficit, which should theoretically and ideally be measured above the vegetation in the layer of the atmosphere constantly modified by evapotranspiration (surface boundary layer) and various meteorological station values (short and well-watered lawns).

Some models exist for the estimation of air saturation deficit from the characteristics of the planetary boundary layer, a global layer subject to the exchange of energy and mass with the surface but not yet subject to the Earth's rotation (20-40 m at night and up to 3,000 $m$ during the day).

\section{Study sites and measurements}

Study sites field work was carried out:

1) On a 1-ha plot (Fig. 2) situated on a dune's rise (including the dune's crest and hollow with $1.6 \%$ slope). The plot was located near Souilène, about $400 \mathrm{~km}$ from Dakar and $20 \mathrm{~km}$ from Dagana $\left(16^{\circ} 20^{\prime} 30^{\prime} \mathrm{N}, 15^{\circ} 25^{\prime} 40^{\prime} \mathrm{W}\right)$. The study area is a Sahelian zone 
in the northern Ferlo region (North Senegal, West Africa). The climate of the region is dry tropical with mean annual precipitation (1918-1990, Dagana) of $282 \mathrm{~mm}$ year $^{-1}$. This Mimosaceae thorn scrub has three main vegetation layers: a herbaceous layer (mainly composed of annual grasses) dominated by shrub and small trees layers. The landscape is typically a gently undulating surface composed of low magnitude nonoriented dunes that end in small hollows. The overstore canopy is mainly 20 year old Acacia tortilis (Forsk.) Hayne ssp raddiana (Savi) Brenan and 25 year old Balanites aegyptiaca (L.) Del; stand density is 151 trees $\mathrm{ha}^{-1}$ and the total basal area is $3.87 \mathrm{~m}^{2} \mathrm{ha}^{-1}$. On the 1 ha plot we seleted agrove with Acacia tortilis, a grove with Balanites aegyptiaca and a herbaceous zone outside the tree ccrown shade (without trees). Mean height of Acacia tortilis and Balanites aegyptiaca trees was $6.60 \mathrm{~m}$ and $6.40 \mathrm{~m}$, respectively, and mean stem diameter at soil level was $0.56 \mathrm{~m}$ and $0.61 \mathrm{~m}$. The age of selected trees, (20 and 25 years, respectively) correspond to the most important populations in the pyramid-shaped diagrams representing the populations of Acacia tortilis and Balanites aegyptiaca by age-groups. Every grove possessed its characteristic herbaceous layer (annuals). The plot's soils belong to the brown sub-arid sandy soils which are slightly acid $(\mathrm{pH}$ 6-6.5) and poor in clay, organic matter, nitrogen and phosphorus. The study zone is a rangeland with average annual primary production of the herbaceous layer $\left(2895 \mathrm{~kg} \mathrm{DM} \mathrm{ha}^{-1}\right.$ year $\left.^{-1}\right)$ being $10 \%$ lower than the actual demand of the grazing livestock. The continuous livestock presence destroys the crust at the soil surface and promotes infiltration of rainfall.

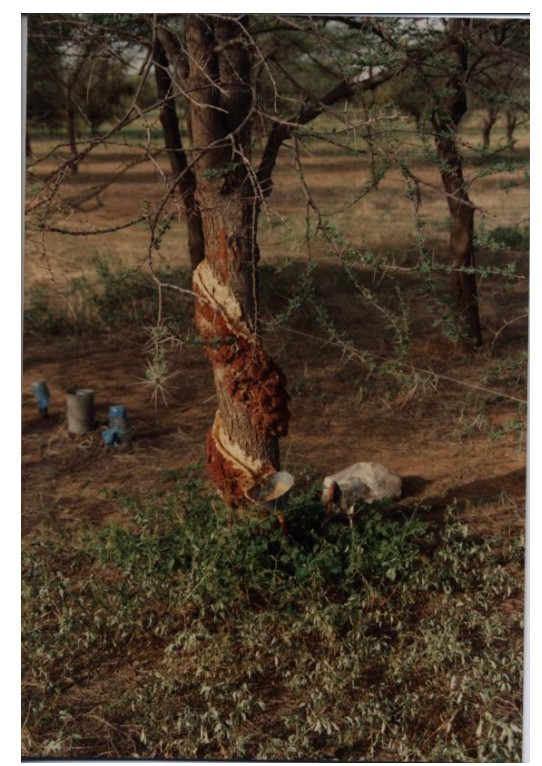

Figure 2. Experimental site located in the Ferlo region (northern Senegal). Landscape formed by a very open thorny steppe, including a herbaceous layer composed of annual species, dominated by grasses (average dry-matter yield, 2,895 $\mathrm{kg} \mathrm{ha}^{-1}$ year-1) and dotted with trees and shrubs (Acacia tortilis and Balanites aegyptiaca) with an average height of $6.5 \mathrm{~m}$, a density of 151 trees $\mathrm{ha}^{-1}$, and a total basal area of $3.87 \mathrm{~m}^{2} \mathrm{ha}^{-1}$ (Nizinski et al., 1994)

(2) On two plots located (Fig. 3a) near Kondi (latitude $4^{\circ} 34^{\prime}$ 'S, longitude $11^{\circ} 54^{\prime} \mathrm{E}$, altitude 80-120 m above sea level), about $40 \mathrm{~km}$ north from Pointe Noire (Congo). The Kouilou region (covered $13315 \mathrm{~km}^{2}$ ) is situated on the Atlantic Ocean front of the Congo between Cabinda in the South and Gabon in the North; the climate of the region 
is subequatorial tropical with mean annual rainfall $P i_{49-98}=1188 \mathrm{~mm}$, potential evapotranspiration $E p_{92-98}=1390 \mathrm{~mm}$ year $^{-1}\left(E p_{92-98}=3.8 \mathrm{~mm}\right.$ day $^{-1} ; E p_{\text {RAINY }}$ SEASON $=4.2 \mathrm{~mm} \mathrm{day}^{-1}, E p$ DRY SEASON $=3.2 \mathrm{~mm} \mathrm{day}^{-1}$ ), mean air temperature $24.9{ }^{\circ} \mathrm{C}$ $\left(t_{\max }=28.2^{\circ} \mathrm{C}, t_{\min }=21.9^{\circ} \mathrm{C}\right)$, relative air humidity $81.1 \%\left(H_{\max }=95.5 \%\right.$, $H_{\min }=66.4 \%$ ) (long-term values estimated over the period of 1949-98, meteorological station, Pointe Noire). The rainy season, which lasts about 180 days, starts in November and ends in April, the dry season from June to September; May and October are the months of transition. The study area is situated on thick detritic formations of continental origin, dating from the pliopleistocene. The soils are ferrallitic and highly desaturated, on sandy to sandy clay material (grayish-ochre colour, more than $90 \%$ of sand content and particular structure).

Sampling and measurement techniques: water balance, plant water status and environmental measurements

- Weekly measurements: gross precipitation, throughfall (22 rain gauges "Association"; collecting area $8800 \mathrm{~cm}^{2}$ ), stemflow (10 stemflow collars), soil water content (neutron probe "Solo25", Centre d'Etudes Nucléaires, Cadarache, France; 8 permanent access tubes).

- Hourly measurements: leaf water potential (pressure chamber PMS, Inst. Co., Corvallis, Oregon, USA), leaf transpiration, stomatal resistance (porometer AP4, Delta-T-Devices, UK), soil water potential (tensiometers, Soil Moisture Equipment Corporation, Oh, USA).

- Leaf area index (Fig. 3b): maximal leaf area index and leaf area distribution will be reported, the total leaf area divided by the area covered by the leaf area, obtained by direct measurements of the number of leaves of the year harvested (litter fresh).

- Stomatal resistance $\left(\mathrm{r}_{\mathrm{s}}\right)$ : measurements were made using an AP4 porometer, Delta-T-Devices ${ }^{\circledR}$ (Fig. 4). Porometers measure gaseous exchanges between the leaf and the atmosphere. These fluxes are proportional to the surface of the leaf, to the concentration gradients of the gas between the inside and the outside of the leaf, and to the conductivity (=1/ resistance) of the leaf. In open systems, a constant flow of air and a known water vapor concentration enters the chamber where the leaf is located, and the concentration of outgoing water vapor is then measured. It is then possible to calculate perspiration and stomatal resistance.

\section{Results and discussion}

Impact of leaf area index on actual evapotranspiration: The actual/potential evapotranspiration ratio increases with increasing leaf area index according to the function:

$$
\mathrm{E}_{\mathrm{a}} / \mathrm{ET}_{0}=1-\mathrm{e}^{(-\mathrm{kLAI})}
$$

where $\mathrm{k}$ is the extinction coefficient of light in the cover (Saugier, 1996) and LAI is leaf area index $\left(\mathrm{m}^{2} \mathrm{~m}^{-2}\right)$.

Depending on the type of vegetation, the differences in this curve $(E q .7)$ are larger or smaller. The measurement and modelling of leaf area index are therefore essential. 
We will illustrate the influence of leaf area index on actual evapotranspiration with two situations: a temperate oak forest, representing a deciduous forest that we followed several years from bud break until the leaves fell, and the Sahelian steppe, representing heterogeneous vegetation.

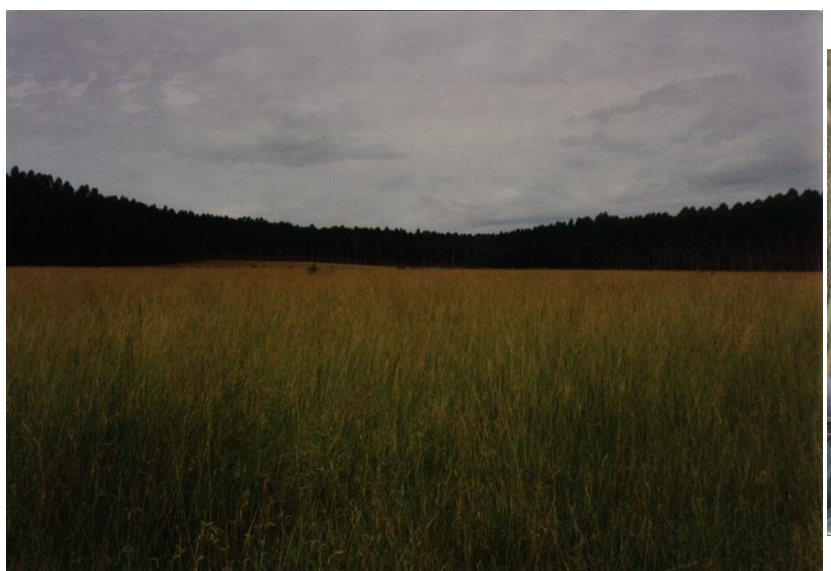

a

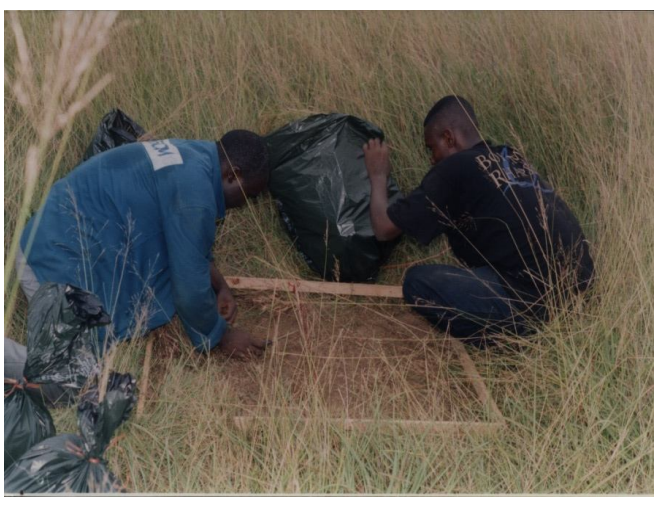

b

Figure 3 a. Experimental site located in the watershed of Kouilou on the Atlantic coast of Congo (view from the study site). $\boldsymbol{b}$. LAI measurement of savannah $90 \%$ dominated by Loutetia arundinacea (average height, $1.5 \mathrm{~m}$; maximum biomass, 3.5 tonnes $\mathrm{ha}^{-1}$; maximum dead biomass, 4.6 tonnes $h a^{-1}$; leaf area index, 4.3; root zone, $3 \mathrm{~m}$ in depth; field capacity $\left(R_{F C}\right)$, $363 \mathrm{~mm}$; permanent wilting point $\left(R_{W P}\right), 182 \mathrm{~mm}$; available water content $\left.\left(R_{A W}\right), 181 \mathrm{~mm}\right)$

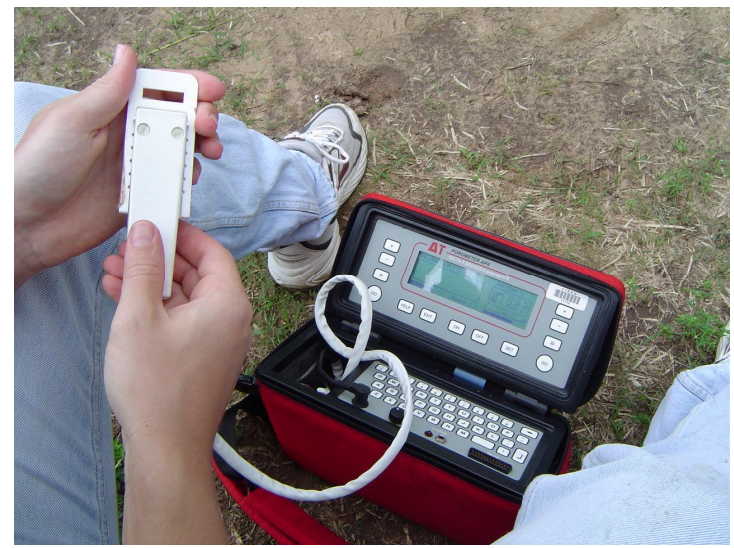

Figure 4. Stomatal resistance measurements were made using an AP4 porometer, Delta-TDevices ${ }^{\circledR}$

For the savannahs (Sahelian steppe, Fig. 2; savannah of the Congolese littoral, Fig. $3 a$ ), we estimated $\mathrm{g}_{\mathrm{a}}$ from the profiles of the wind speeds above these herbaceous covers (from 2.5 to $5.0 \mathrm{~cm} \mathrm{~s}^{-1}$ ).

The overall values of aerodynamic resistance reflect the fact that resistance decreases with roughness of the canopy and wind speed. For sparse vegetation, no formula has been developed as yet for the calculation of aerodynamic resistance. For the Sahelian steppe, composed of $80 \%$ herbaceous areas (groves of low trees), we assumed the equality of aerodynamic resistance in herbaceous zones and groves, which, given the 
low density of trees within groves, is reasonable: resistance is even higher than density is low; otherwise, regarding estimates of interception (in which only aerodynamic resistance occurs), it can be assumed that there is no overestimation here either, because rains are of great intensity and the water retention capacity of crowns and trunks is low (2.9-3.8 mm for Balanites aegyptiaca and Acacia raddiana, respectively) (Fig. 2).

The maximum values of interception of Balanites aegyptiaca and Acacia raddiana groves equal 8.4 and $12.4 \%$ of incident rainfall (Pi), respectively. These values can reach $40 \%$ of Pi for oaks in the temperate zone (forest of Fontainebleau). The maximum values of interception of groves ( 8.4 and $12.4 \%$ of $\mathrm{Pi}$, respectively) are of the same order of magnitude as that of the herbaceous zones of the Sahel savannah $(7.5 \%$ of $\mathrm{Pi})$ (Fig. 2) and the savannah of the Congolese littoral (7\% of Pi) (Fig. 3a).

In the case of deciduous species, it is a question of modelling various phenological stages: the day of bud burst; the period of leaf growth up to maximum leaf area index; the adult phase during which the leaf area index is equivalent to the maximum value $\left(\mathrm{LAI}=\mathrm{LAI}_{\max }\right)$; the beginning of senescence from the first fall of leaves until the leaf area index equals zero. For Quercus petraea, using two simple input variables [mean air temperature and photoperiod] we modelled the day of budburst, the day marking the end of surface growth of the leaves, and the evolution of leaf area index.

In terms of the relationship of minimal stomatal resistance to leaf area index in deciduous species, with the exception of Eucalyptus, the species we studied are deciduous. The leafless period is the cold season in the temperate zone and the dry season in the tropical zone. Thus we were able to analyse the following phenomenon: when setting up the canopy, the minimal stomatal resistance of a leaf decreases with increasing leaf area index and generally continues to decrease to its minimum value as long as the leaf area index is maximal (Fig. 5). The leafless period may be longer or shorter depending on the species $\left(\mathrm{LAI}_{\max }\right.$ - minimum values $\mathrm{r}_{\mathrm{st} \text {-min }}$; in Quercus petraea, LAI $=100 \%, \mathrm{r}_{\mathrm{st}-\min }=3.6 \pm 0.9 \mathrm{~s} \mathrm{~cm}^{-1}$ and LAI $=8 \%, \mathrm{r}_{\mathrm{st}-\min }=8.7 \pm 3.6 \mathrm{~s} \mathrm{~cm}^{-1}$, respectively) (Fig. 6a-d); for example, in oaks, it is very short (two to three weeks). Subsequently, $\mathrm{r}_{\mathrm{st}-\mathrm{min}}$ increases throughout the period of $\mathrm{LAI}_{\max }$ (two and a half months for the oak) and continues to increase during senescence.

In deciduous forests, actual evapotranspiration follows changes in leaf area index; as there is a gap between the points when LAI $=\mathrm{LAI}_{\max }$ and when $\mathrm{r}_{\text {st-min }}$ reaches its minimum value, actual evapotranspiration reaches its maximum (when not subjected to water stress) when $r_{\text {st-min }}$ is at its minimum value for oaks, i.e. about a month after LAI $=$ $\mathrm{LAI}_{\max }$ (Fig. 7).

Balanites aegyptiaca offers an example of adaptation to drought. To summarise the characteristics that may explain its distribution (this species 'goes up' to the northernmost part of Senegal) and the current increase in its frequency compared to other shrub and tree species of the Sahelian steppe: in the dry season, when water availability becomes limited, we observed that Balanites aegyptiaca employed a strategy of maintaining high leaf water potential through increased stomatal resistance ('ABA message' from the roots) and a leaf area index modification strategy (falling leaves). Thus, at the end of the dry season when Balanites aegyptiaca no longer has leaves, soil water that was available but not used (increased stomatal resistance, decreased transpiration) remains in the deep layers of the soil (deeper than $2.0 \mathrm{~m}$ ).

Subsequently, bud break and leaf growth occur prior to the rainy season, during a period when the relative air humidity increases; this leaf growth is possible because there is water available deep in the soil. 
This leads us to make two assumptions:

(1) We posit the existence of a chemical 'message' related to detection of the increase in relative air humidity. This message participates in the chemical equilibrium of induction at bud break. This detection must be performed by an above-ground organ, possibly the photosynthetic stalk (thorns), which remains in place.

(2) We suppose that this message has priority over the 'ABA message' from the roots, since the leaves are being put in place while the soil water content of the upper layers are at the permanent wilting point, in 'soil conditions' identical to those of the end of the dry season. Here, we can question the adaptive advantage of setting up the leaves prior to the arrival of the rainy season.

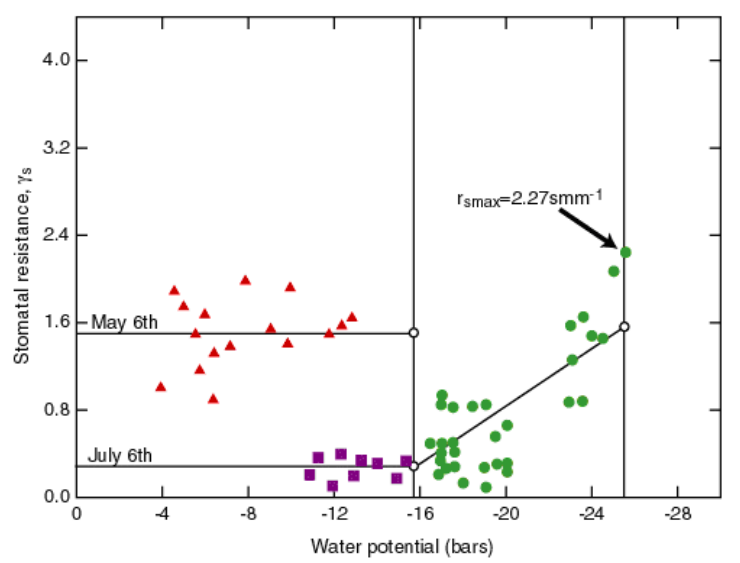

Figure 5. Evolution of minimal stomatal resistance $\left(r_{\text {st-min }}, \mathrm{s} \mathrm{cm}^{-1}\right)$ with leaf water potential $\left(\Psi_{m}\right.$, bars) for oak leaves in the forest of Fontainebleau and in the park of the Orsay University of during the growing seasons of 1983 and 1987 , respectively $\left(r_{s t-m i n}=78.501 S F^{-0.7505} ; r^{2}=0.905\right.$;

$$
N=12)
$$
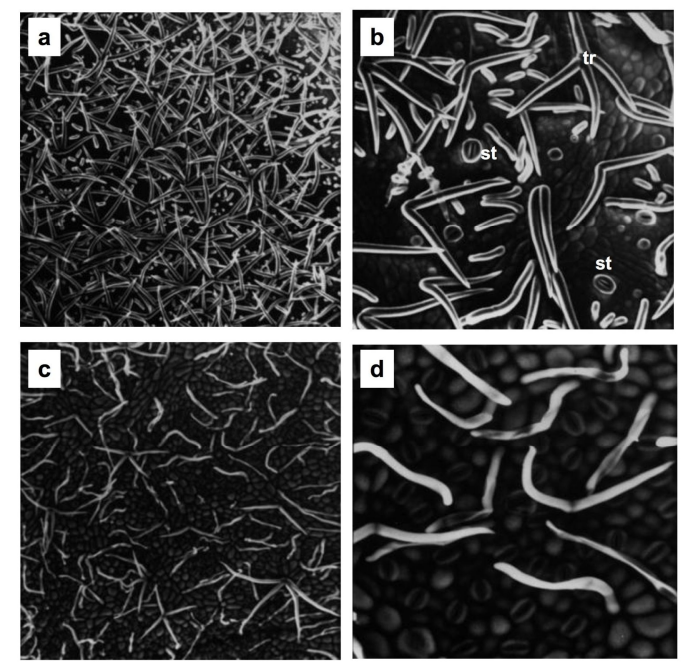

Figure 6 a-d. Images acquired via scanning electron microscopy showing two morphological stages of stomata and trichomes of Quercus petrea leaves growing in the park of the Orsay University: $\boldsymbol{a}$ low- and $\boldsymbol{b}$ high-resolution images for the morphological stage of 24 April 1987 $\left(S F=8 \%\right.$ of $\left.S F_{\max }, r_{\text {st-min }}=8.7 \pm 3.6 \mathrm{sm}^{-1}, N=50\right)$; $c$ low- and $\boldsymbol{d}$ high-resolution images for the morphological stage of 14 May $1987\left(S F=100 \%\right.$ of $\left.S F_{\max }, r_{s t-\min }=3.6 \pm 0.9 \mathrm{~s} \mathrm{~cm}^{-1}, N=50\right)$.

The location of some stomatas (st) and trichromes (tr) is indicated in $\boldsymbol{b}$ 


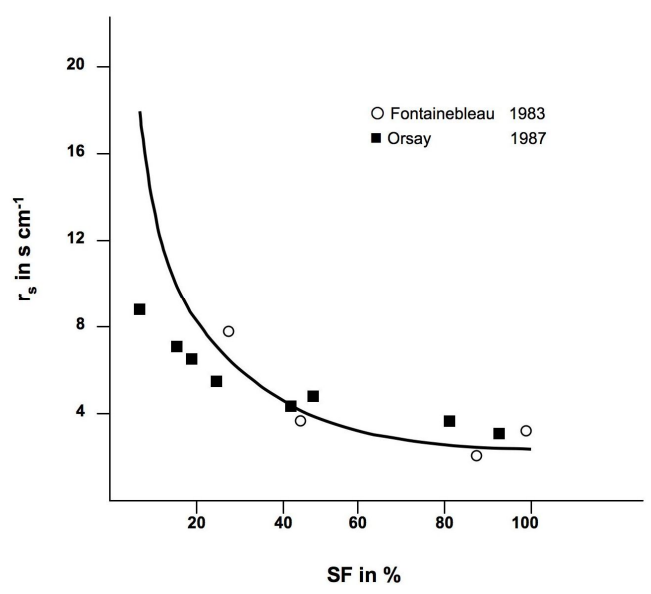

Figure 7. Evolution of minimal stomatal resistance $\left(r_{\text {st-min }}, \mathrm{s} \mathrm{cm}^{-1}\right)$ along with leaf area (SF, \%) for oak leaves during the growing season of 1983 in the forest of Fontainebleau

\section{Conclusion}

Humankind has changed and continues to change plant cover; globally, there has been an increase in herbaceous and bare-soil areas to the detriment of areas that had been populated with trees and shrubs since the Neolithic. Changes in vegetation cover have involved changes in local and regional climates as well as in the global climate.

Climate models of the general circulation of the atmosphere require actual evapotranspiration models which incorporate 'vegetation-atmosphere' exchanges as realistically as possible. Our studies of Acacia raddiana and Balanites aegyptiaca in the steppes of Senegal (Nizinski et al., 1994) and of Loudetia arundinacea in the savannah and eucalyptus plantations on the coast of the Congo (Nizinski et al., 2011) offer two examples of the impact of a change in cover on actual evapotranspiration: in Senegal, the groves of the steppe ( $20 \%$ of the surface) may be assimilated into the 'clear forest' of Acacia senegal in Northern Senegal before this forest disappears and an $80 \%$ herbaceous area represents the new ecosystem.

In Congo, on the coast, there are remnants of pure savannah adjoining the planted eucalyptus forests in the original savannah. The replacement of the forest with a herbaceous ecosystem is increasing drainage and reducing actual evapotranspiration over a complete cycle of vegetation (with seasonal variations which may be marked, since the two ecosystems differ less in periods of water deficit than in wet seasons, when evaporation of intercepted water is greater in the forest due to its high degree of roughness).

For example, the 'boundary layer resistance' of the Congolese savannah is $\mathrm{Z}_{\mathrm{H}} \approx 3.0 \times$ stand height of plant cover in the case of sensible heat flux, and $Z_{\lambda \mathrm{E}} \approx 3.5 \times$ stand height of plant cover in the case of latent heat flux. Methodologically, any fetch effects should be omitted, so that classical aerodynamic formulas can be applied.

The surface conductance of the two covers differs little; what differs is aerodynamic conductance, in which the two covers differ by a factor of two (from 2.5 to $5.0 \mathrm{~cm} \mathrm{~s}^{-1}$ for 'herbaceous' and from 5.0 to $10.0 \mathrm{~cm} \mathrm{~s}^{-1}$ for 'forest'). The two covers also differ in their albedo (superior in the case of the herbaceous ecosystem) and energy balance (inferior in the case of the herbaceous ecosystem). Actual evapotranspiration of the 
herbaceous ecosystem depends mostly on net radiation, actual evapotranspiration of the forest on deficit of air saturation.

Soil plays a major role: the surface state of the soil governs the existence (or absence) of runoff due to the presence (or absence) of a crust on the soil surface in sparse herbaceous ecosystems. The steppe occupied by Acacia raddiana in the first year after the experimental plot was set aside was characterised by a crust on the soil surface and non-renewal of the herbaceous layer, because this surface was no longer being trampled by herds of animals; in the second year, weeds replaced trampling. The hydraulic conductivity of the saturated soil also governs the existence (or absence) of runoff; this variable is generally lower in herbaceous ecosystems, which are often subjected to trampling by animals, than in forests.

The depth of soil colonised by tree roots is generally greater than that of soil colonised by grass roots: available water remaining in the soil of the steppe occupied by Acacia raddiana could be used if the steppe was forested. Lean and Rowntree (1997) give an example of the replacement of a forest (Amazon rainforest) with a meadow, pointing out that reducing the depth of the exploited soil does not affect the water balance. The Amazon rainforest contains areas where the potentially exploitable soil around the roots is shallow (existence of an impermeable horizon for the roots). In this case the forest has little available soil water content comparable to that of the grassland which succeeds it and whose soil is often characterised by significant underground water circulation. Here we see the importance of soil in regional water balance.

In models of global change, the course of the general circulation of the atmosphere is dependent on the planetary distribution of sources and sinks of energy; during periods of balance, energy is transported by atmospheric air and the water of the oceans. The atmosphere must thus transport the energy of the continents towards the oceans during the summer and that of the oceans towards the continents during the winter.

The study of these phenomena on the continents employs data relating to studies of actual evapotranspiration on a local level, which is the level presented here. Recent models of actual evapotranspiration dissociate evaporation of the soil, canopy transpiration, and interception, and simulate the evolution of the structure of cover, stomatal resistance, and factors which govern the vapour water flux resistances and the balance between evaporation and transpiration. In today's models which take a mechanistic approach, the difficulty of choosing income parameters has become significant, especially the problem of their initial state under a given set of environmental conditions. Currently, from a methodological point of view, for shrubs and tree species, estimation of the transpiration of individual trees using the sap-flow method opens up new perspectives.

The aim of the work described in this paper is to highlight the quality and relevance of the Penman-Monteith model. Nevertheless, on the one hand, even for continuous covers, it is necessary to refine the parameters of the canopy resistance. On the other hand, it was relevant to check the Penman Monteith model for sparse covers crops using the field experience (here the savannahs of the Sahel and the Atlantic coast of Congo); this model makes it possible to account for the actual evapotranspiration of closed plant cover (woody plants) and can be adapted to sparse cover (woody herbaceous savannah with bare soil surfaces) by treating leaf transpiration and evaporation of bare soil separately.

We conclude by stating that the fieldwork parallel to the modelling work is far from complete. We have shown that, for Quercus petraea, there is a factor of three between 
the minimum and maximum values of minimal stomatal resistance or from the range that one may assume very extensive drought adaptation characteristics such as those described for Balanites aegyptiaca.

\section{REFERENCES}

[1] Allen, R. G., Pereira, L. S., Raes, D., Smith, M. (1998): Crop Evapotranspiration: Guidelines for Computing Crop Water Requirements. - Paper no. 56. Food and Agriculture Organization, Rome, Italy.

[2] Jarvis, P. G. (1976): The interpretation of the variations in leaf water potential and stomatal conductance found in canopies in the field. - Philosophical Transactions of the Royal Society of London, Series B, 273: 593-610.

[3] Katerji, N. Perrier, A. (1985): Détermination de la résistance globale d'un couvert végétal à la diffusion de la vapeur d'eau et de ses différentes composantes. Approche théorique et vérification expérimentale sur une culture de luzerne. - Agricultural Meteorology 34: 105-120.

[4] Lean, J., Rowntree, P. R. (1997): Understanding the sensitivity of a GCM simulation of Amazonian deforestation to the specification of vegetation and soil characteristics. Journal of Climate 10: 1216-1235.

[5] Monteith, J. L. (1965): Evaporation and Environment in the State and Movement of Water in Living Organisms. - Proceedings of the Soc. Exp. Biol., Symposium No. 19. Cambridge Univ. Press, Cambridge, pp. 205-234.

[6] Monteith, J. L., Unsworth, M. H. (1990): Principles of Environmental Physics (2 ${ }^{\text {nd }}$ Ed.). Edward Arnold, London.

[7] Niziński, J. J., Morand, D., Saugier, B. (1989): Variation of stomatal resistance with leaf age in Quercus petraea: effect on the soil-water balance of an oak forest. - Annales des Sciences Forestières 46(suppl.): 429-432.

[8] Niziński, J. J., Morand, D., Fournier, C. (1994): Actual evapotranspiration of a thorn scrub with Acacia tortilis and Balanites aegyptiaca (North Senegal). - Agricultural and Forest Meteorology 69: 93-111.

[9] Niziński, J. J., Galat, G., Galat-Luong, A. (2011): Water balance and sustainability of Eucalyptus plantations in the Kouilou basin (Congo-Brazzaville). - Russian Journal of Ecology - Ekologiya 42: 40-50.

[10] Penman, H. L. (1948): Natural evaporation from open water, bare soil, and grass. Proceedings of the Royal Society of London, Series A 193: 120-145.

[11] Saugier, B. (1996): Evapotranspiration des prairies et des cultures. - Comptes Rendus de l'Académie d'agriculture de France 82: 133-153.

[12] Saugier, B., Katerji, N. (1991): Some plant factors controlling evapotranspiration. Agricultural and Forest Meteorology 54: 263-277. 